\title{
Decision Analysis for Management of Vertical Root Fracture
}

\author{
Akshay Khandelwal ${ }^{1}$, Ajitha Palanivelu² \\ 1,2 Department of Conservative Dentistry and Endodontics, Saveetha Dental College and Hospitals, \\ Saveetha Institute of Medical and Technical Sciences, Chennai, Tamil Nadu, India.
}

\section{ABSTRACT}

Vertical root fracture is usually seen in endodontically treated teeth with or without post, and presents a great challenge in diagnosis and treatment. The clinical presentation and low sensitivity of periapical radiographs make the diagnosis of vertical root fracture one of the most difficult conundrums for dentists. The clinical signs and symptoms of a vertical root fracture are extremely variable. They vary according to the position of the fracture, tooth type, time after fracture, the periodontal condition of the tooth and the status of adjacent bone. The predisposing factors for vertical root fracture may be natural or iatrogenic. Natural factors include thin cross sections of root, pre-existing micro cracks etc. and iatrogenic factors include excessive root canal preparation, micro cracks by rotary and reciprocating instruments, excessively thick posts etc.

Radiographs being two dimensional representations are of limited use due to superimposition of the fracture line by the filling material. Multiple radiographs taken in different angulations are recommended to be taken after removal of the filling material. Cone Beam Computed Tomography provides a three-dimensional replication of tooth with VRF helping in better assessment of such fractures.

If not diagnosed, vertical root fracture can lead to frustration and improper endodontic treatment. Although difficult, a systematic diagnostic approach with a thorough clinical and radiographic evaluation may help in the early diagnosis of vertical root fracture. An accurate and timely diagnosis of vertical root fracture will allow extraction of tooth before extensive damage to adjacent alveolar bone can happen. This decision-analysis-article aims to discuss clinical and radiographic features of vertical root fracture and how cone beam computed tomography can help in its diagnosis. It also discusses the predisposing factors, treatment and measures to prevent vertical root fracture.

\section{KEY WORDS}

Vertical Root Fracture, Root Fracture, Decision Analysis, VRF, CBCT
Corresponding Author: Dr. Ajitha Palanivelu, Department of Conservative and Endodontics, Saveetha Dental College and Hospitals, Saveetha Institute of Medical and Technical Sciences, \# 162, Poonamalle High Road, Chennai - 600077, Tamil Nadu, India.

E-mail: ajitharijesh@gmail.com

DOI: $10.14260 / j e m d s / 2020 / 760$

How to Cite This Article:

Khandelwal A, Palanivelu A. Decision analysis for management of vertical root fracture. J Evolution Med Dent Sci 2020;9(46):3474-3478, 10.14260/jemds/2020/760

Submission 04-06-2020,

Peer Review 03-10-2020,

Acceptance 09-10-2020,

Published 16-11-2020.

Copyright (C) 2020 JEMDS. This is an open access article distributed under Creative Commons Attribution License [Attribution 4.0 International (CC BY 4.0)] 


\section{BACKGROUND}

A Vertical Root Fracture (VRF) is a longitudinally oriented complete or incomplete fracture initiated in the root at any level and is usually detected bucco-linngually. ${ }^{1}$ Vertical root fracture is the third most common reason for extraction of a tooth that is endodontically treated. ${ }^{2}$ Vertical root fracture is an important threat to the tooth's prognosis during and after root canal treatment.

It is difficult to diagnose vertical root fracture. The clinical signs and symptoms resemble a lot with split tooth, localised periodontitis, endo-perio lesion, apical periodontitis or a nonhealing root canal treated tooth. It is important to differentially diagnose vertical root fracture from such conditions. Diagnosis of vertical root fracture radio graphically is also difficult as the radiographic patterns of per radicular bone destruction are also shared by other periodontic and endodontic lesions. In early stages there may be no radiolucent bone lesions observed delaying the diagnosis and treatment of vertical root fracture. Most VRFs are in buccolingual direction, the radiopaque obturating material often obstructs the view of hairline radiolucency of the fracture. An accurate diagnosis also depends on the angulation, contrast, density and the expertise of the clinician interpreting the radiograph. Diagnosis of vertical root fracture is only possible with cumulative input from history, clinical signs and symptoms and radiographic evaluation.

Cone Beam Computed Tomography (CBCT) has a high accuracy and sensitivity in detecting vertical root fractures. ${ }^{3-11}$ CBCT has ability to assess a tooth and adjacent bone in axial plane, providing a cross sectional view. The detection of VRF by CBCT greatly depends on the resolution of the machine i.e. voxel size, a decrease in voxel size increases the reliability. ${ }^{12-16}$ An accurate and early diagnosis of VRF allows extraction of the tooth or the required root before extensive destruction of the surrounding per radicular structures like alveolar bone. Preserving the alveolar bone can help in future restorative procedures like implant.

\section{Clinical Signs and Symptoms of VRF}

Most commonly associated with root canal treated teeth with or without post. ${ }^{17}$ The most susceptible teeth groups are maxillary and mandibular premolars, mesial roots of mandibular molars, mesiobuccal root of maxillary molars and mandibular incisors. In early stages the tooth may present with dull pain on chewing. As the fracture and the subsequent infection progresses, the tooth may present with a swelling and / or a sinus tract which is more coronally located compared to sinus tract associated with chronic apical abscess which is usually present at the junction of attached gingiva and oral mucosa. ${ }^{18}$ Presence of a deep, narrow, and isolated pocket is usually seen in buccal and lingual aspect of teeth with VRF. A rigid probe may be of limited value in evaluating such pockets as the bulge of the crown will prevent the insertion of probe into deep, tight pocket. A flexible post is more likely to detect VRF pockets at an early stage.

\section{Radiographic Features of VRF}

VRF can be confirmed sometimes by radiographic presentation of thin radiolucent line extending longitudinally down the root. ${ }^{17}$ Such line are usually not visible in a radiograph due to improper angulation or obstruction by root canal filling. A j-shaped or hallow appearance by a combination of periapical and per radicular radiolucencies, ${ }^{17}$ dislodgement of retro-filling material, ${ }^{19}$ angular resorption of the crestal bone, ${ }^{20}$ separation of root fragments ${ }^{21}$ or displacement of apical portions of $\operatorname{root}^{22}$ are pathognomonic radiographic features of VRF. When suspecting a VRF, the clinician should initiate root canal retreatment, remove the root filling and then take radiographs in two or three horizontal angulations for radiographic diagnosis of VRF.

\section{Exploratory Surgery}

When clinical and radiographic evaluations are ambiguous in detection of a suspected VRF, exploratory surgery is recommended. A full thickness flap has to be raised and granulation tissue has to be removed to directly visualise presence of VRF line. Bony dehiscence in majority of cases and fenestrations in a few cases are the bone resorption pattern in cases of vertical root fractures. ${ }^{23,24}$

\section{Histopathogenesis of Vertical Root Fractures} Pockets associated with VRFs develop due to bacterial penetration into the fracture line which causes destructive inflammatory host response in the adjacent periodontal tissues. These bacteria can be from the infected root canal or from the oral cavity if the VRF is extending coronally. ${ }^{25}$

\section{PREDISPOSING FACTORS FOR VERTICAL} ROOT FRACTURES

\section{NATURAL PREDISPOSING FACTORS}

Shape of Root Cross Section - In oval shaped canal usually the buccolingual diameter is more than mesiodistal diameter; the strain concentration on the inner side of the remaining dentin wall at the highest convexity in the buccal and lingual sides is very high. ${ }^{26-28}$ Teeth with oval shaped root canals are at higher risk of VRF. ${ }^{29}$

Occlusal Factors - Excessive occlusal loads or high concentration of such loads at a specific point can be another predisposing factor. This can be due to malocclusion or due to improper load sharing among the teeth. ${ }^{1}$

Pre-Existing Micro Cracks - Pre-existing micro cracks may be present in radicular dentin due do parafunctional habits or repeated heavy occlusal loads.

\section{IATROGENIC PREDISPOSING FACTORS}

Root Canal Treatment - VRF is mostly associated with endodontically treated teeth. ${ }^{30}$ previously it was believed that teeth undergoing endodontic treatment become more prone to fracture because of decrease in hydration. This was later proven to be wrong as studies found out that there is no difference in the properties of dentin as a material after 
endodontic treatment. ${ }^{31}$ Although the physical properties of dentin as a material are not compromised, radicular dentin is compromised structurally in endodontic treatment.

Excessive Root Canal Preparation - Excessive root canal preparation for shaping the canals or post placement makes a tooth highly susceptible to VRF.27,28,32

Micro Cracks Caused by Rotary / Reciprocating Instruments - Root canal treatment using rotary or reciprocating nickel titanium files often result in micro cracks formation in residual radicular dentin. ${ }^{33}$ These micro cracks can propagate under heavy occlusal stresses, predisposing the tooth to VRF.

Type of Spreader Used - Use of a thick, rigid stainlesssteel hand spreader might exert undue stresses on the root dentin increasing the chances of VRF. ${ }^{29}$ Use of flexible smaller size finger spreaders made up of nickel titanium reduces such risks.

Method of Obturation - Obturation techniques like lateral condensation exert a lot of strain on radicular dentin which might propagate micro cracks into fractures across full dentin thickness.17,18,34 Thermoplasticized gutta-percha techniques like Obtura and Thermafil also caused thermal expansion of root dentin but the chances of VRF is considerably low. 35

Post Design - The rigidity, design and seating of a post have a significant contribution to the strain distribution in the root $^{36}$ extremely rigid, long and thick posts are considered predisposing factors for VRF. Ferrule plays an important role too, crowns with adequate ferrule shows better stress distribution.

\section{Role of CBCT in Diagnosis of VRF}

CBCT provides a 3-dimensional volumetric data, thereby allowing precise visualisation and evaluation of a tooth with VRF. CBCT shows more sensitivity, specificity, and accuracy in diagnosis of VRF compared to periapical radiographs (PR). ${ }^{4-10}$ The pooled sensitivity, specificity and diagnostic odds ratio (DOR) of CBCT and PR as reported in meta-analysis by Talwar et al. (Table 1) showed better sensitivity, specificity of CBCT than PRs in detection of VRF in unfilled teeth. ${ }^{11}$

\begin{tabular}{|ccccc|}
\hline $\begin{array}{c}\text { Imaging } \\
\text { Technique }\end{array}$ & $\begin{array}{c}\text { Status of } \\
\text { Root Filling }\end{array}$ & Sensitivity & Specificity & DOR \\
CBCT & Filled & 0.752 & 0.652 & 5.527 \\
& Unfilled & 0.766 & 0.946 & 94.26 \\
PR & Filled & 0.242 & 0.961 & 8.586 \\
& Unfilled & 0.425 & 0.939 & 14.42 \\
\hline Table 1. The Pooled Sensitivity, Specificity, and Diagnostic Odds Ratio \\
(DOR), of CBCT and PR for Detection of VRF as Reported in the \\
Meta-Analysis by Talwar et al. ${ }^{11}$ \\
\hline
\end{tabular}

The higher overall DOR for CBCT than PR in the detection of VRF in unfilled teeth shows that odds of correctly diagnosing VRF is more by CBCT than PR in unfilled teeth. This can be because CBCT allow a three-dimensional visualisation of VRF teeth at different angulations and orientations at very high contrast. The presence of filling reduces the sensitivity of PR which can be explained by the fact that presence of radiopaque root filling blocks the vision of radiolucent fracture line. Although the presence of filling does not significantly reduce the sensitivity of CBCT in assessing VRFs, it significantly reduces its specificity. This is because radiopaque endodontic filling material cause artifacts making it difficult to assess VRF.

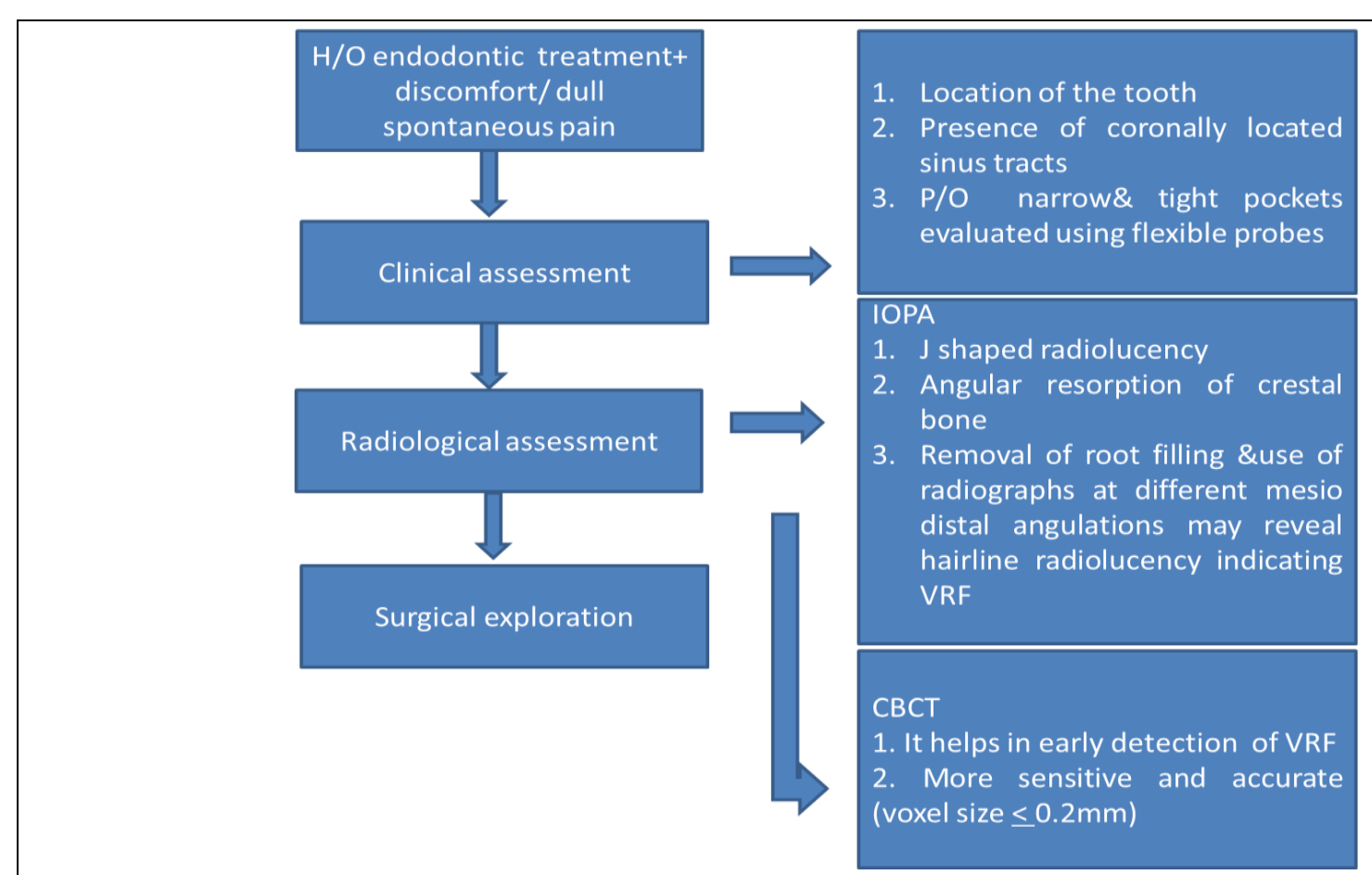

Figure 1. Flowchart - Decision Making for VRF 
Evidence has shown difference in diagnostic accuracy among different CBCT systems. The accuracy is related to voxel size, field of view and resolution. CBCT with voxel size $\leq$ $0.2 \mathrm{~mm}$ has been found to be more sensitive than conventional radiographs for detection of VRF. ${ }^{11}$

\section{Treatment of VRF}

When VRF is diagnosed in single rooted teeth, extraction of the affected tooth shall be done as soon as possible. A delay will cause additional bone loss compromising placement of dental implants as replacement option. In multi rooted teeth hemi section, raw dissection or root amputation can be carried out in order to remove the root with VRF. Various attempts have been made to repair the fracture by filling the crevice with restorative materials like composites and glass ionomers followed by reimplantation, ${ }^{37-42}$ but none of these procedures have been proven to be a long-term reliable treatment option.

\section{Measures to Prevent VRF}

- Advocating protective appliances like night guards in bruxers will prevent micro crack propagation.

- Minimal preparation of canals for optimal irrigation.

- Use of irrigating solution and EDTA gel while instrumentation minimizes micro crack formation.

- Post space, canal or crown preparation shall aim at conserving pericervical dentin.

- Use of partial coverage restorations when possible.

\section{CONCLUSIONS}

VRF is one of the most difficult conundrums for clinicians to diagnose and treat. An early detection of VRF not only prevents unnecessary endodontic treatment and consecutive frustration on failure, but also saves the adjacent alveolar bone from excessive destruction. A systematic approach with careful clinical examination, radiographic evaluation in multiple angulations, and a CBCT scan can help in successful diagnosis of VRF. Endodontic and restorative treatment should be carried out keeping in mind the predisposing factors for VRF.

Financial or other competing interests: None.

Disclosure forms provided by the authors are available with the full text of this article at jemds.com.

\section{REFERENCES}

[1] American Association of Endodontists. Endodontics: colleagues for excellence-cracking the cracked tooth code. Chicago, IL: American Association of Endodontists Fall/Winter 2008.

[2] Toure B, Faye B, Kane AW, et al. Analysis of reasons for extraction of endodontically treated teeth: a prospective study. J Endod 2011;37(11):1512-5.

[3] Wang P, He W, Sun $\mathrm{H}$, et al. Detection of vertical root fractures in non- endodontically treated molars using cone beam computed tomography: a report of four representative cases. Dent Traumatol 2012;28(4):32933.

[4] Bernardes RA, de Moraes IG, Hungaro Durate MAH, et al. Use of cone - beam volumetric tomography in the diagnosis of root fractures. Oral Surg Oral Med Oral Pathol Oral Radiol Endod 2009;108(2):270-7.

[5] Varshosaz M, Tavakoli MA, Mostafai M, et al. Comparison of conventional radiography with cone beam computed tomography for the detection of vertical root fractures: an in vitro study. J Oral Sci 2010;52(4):593-7.

[6] Valizadeh S, Khosaravi M, Azizi Z. Diagnostic accuracy of conventional, digital and cone beam computed tomography in vertical root fracture detection. Iran Endod J 2011;6(1):15-20.

[7] Edlund M, Nair MK, Nair UP. Detection of vertical root fractures by using cone beam computed tomography: a clinical study. J Endod 2011;37(6):768-72.

[8] Zou X, Liu D, Yue L, et al. The ability of cone - beam computerized tomography to detect vertical root fractures in endodontically treated and nonendodontically treated teeth: a report of 3 cases. Oral Surg Oral Med Oral Pathol Oral Radiol Endod 2011;111(6):797-801.

[9] Tang L, Zhou XD, Wang Y, et al. Detection of vertical root fracture using cone beam computed tomography: report of two cases. Dent Traumatol 2011;27(6):484-8.

[10] Metska ME, Aartman IHA, Wesselink PR. et al. Detection of vertical root fractures in vivo in endodontically treated teeth by cone- beam computed tomography scans. J Endod 2012;38(10):1344-7.

[11] Talwar S, Utneja S, Nawal RR, et al. Role of cone- beam computed tomography in diagnosis of vertical root fractures: a systematic review and meta- analysis. J Endod 2016;42(1):12-24.

[12] Hassan B, Metska ME, Ozok AR, et al. Comparison of five cone beam computed tomography systems for detection of vertical root fractures. J Endod 2010;36(1):126-9.

[13] Ozer SY. Detection of vertical root fractures of different thicknesses in endodontically enlarged teeth by cone beam computed tomography versus digital radiography. J Endod 2010;36(7):1245-9.

[14] Khedmat S, Rouhi N, Drage N, et al. Evaluation of three imaging techniques for the detection of vertical root fractures in the absence and presence of gutta-percha root fillings. Int Endod J 2012;45(11):1004-9.

[15] Diederichs CG, Engelke WG, Richter B, et al. Must radiation dose for $\mathrm{CT}$ of the maxilla and mandible be higher than that for conventional panoramic radiography? AJNR Am J Neuroradiol 1996;17(9):175860.

[16] Hirsch E, Wolf U, Heinicke F, et al. Dosimetry of the cone beam computed tomography veraviewepocs 3D compared with the 3D accuitomo in different field of view. Dentomaxillofac Radiol 2008;37(5):268-73.

[17] Meister F, Lomme TJ, Gerstein H. Diagnosis and possible causes vertical root fractures. Oral Surg Oral Med Oral Pathol 1980;49(3):243-53.

[18] Pitts DL, Natkin E. Diagnosis and treatment of vertical root fractures. J Endod 1983;9(8):338-46.

[19] Farber PA, Green DB. The disappearing amalgam: diagnosis of root fracture. Oral Surg Oral Med Oral Pathol 1973;35(5):673-5. 
[20] Lommel T], Meister F, Gerstein H, et al. Alveolar bone loss associated with vertical root fracture: report of six cases. Oral Surg Oral Med Oral Pathol 1978;45(6):909-19.

[21] Tamse A, Zilburg I, Halpern J. Vertical root fractures in adjacent maxillary premolars: an endodontic - prosthetic perplexity. Int Endod J 1998;31(3):127-32.

[22] Meister F, Lommrl TJ, Gerstein H, et al. An additional clinical observation in two cases of vertical root fracture. Oral Surg Oral Med Oral Pathol 1981;52(1):91-6.

[23] Tamse A, Fuss Z, Lustig J, et al. Radiographic features of vertical fractured, endodontically treated maxillary premolars. Oral Surg Oral Med Oral Pathol Oral Radiol Endod 1999;88(3):348-52.

[24] Tamse A, Kaffe I, Lustig J, et al. Radiographic features of vertically fractured endodontically treated mesial roots of mandibular molars. Oral Surg Oral Med Oral Pathol Oral Radiol Endod 2006;101(6):797-802.

[25] Ross IF. Fracture susceptibility of endodontically treated teeth. J Endod 1980;6(5):560-5.

[26] Goodacre CJ, Spolink KJ. The Prosthodontic management of endodontically treated teeth: a literature review. Part I. Success and failure data, treatment concepts. J Prosthodont 1994;3(4):243-50.

[27] Abdo SB, Darrat AA, Masaudi SM, et al. Comparison of over flared root canals of mandibular premolars filled with MTA and resin based material: an in vitro study. Smile Dent J 2012;7(2):38-40.

[28] Oliet S. Treating vertical root fractures. J Endod 1984;10(8):391-6.

[29] Vertucci FJ. Management of vertical root fracture. J Endod 1985;11(3):126-31.

[30] Barkhodar RA, Kempler D, Knapp J. Mesiodistal root fracture. Three case reports. Oral Surg Oral Med Oral Pathol 1988;65(3):343-8.

[31] Sedgley CM, Messer HH. Are endodontically treated teeth more brittle? J Endod 1992;18(7):332-5.

[32] Selden HS. Repair of incomplete vertical root fractures in endodontically treated teeth--in vivo trials. J Endod 1996;22(8):426-9.
[33] Saw LH, Messer HH. Root strains associated with different obturation techniques. J Endod 1995;21(6):314-20.

[34] Chan CP, Lin CP, Tseng SC, et al. Vertical root fracture in endodontically versus nonendodontically treated teeth: a survey of 315 cases in Chinese patients. Oral Surg Oral Med Oral Pathol Oral Radiol Endod 1999;87(4):504-7.

[35] Lustig J, Tamse A, Fuss Z. Pattern of bone resorption in vertically fractured, endodontically treated teeth. Oral Surg Oral Med Oral Pathol Oral Radiol Endod 2000;90(2):224-7.

[36] Fuss Z, Lustig J, Katz A, et al. An evaluation of endodontically treated vertical root fractured teeth: impact of operative procedures. J Endod 2001;27(1):468.

[37] Hanning C, Dullin C, Hulsmann M, et al. Three dimensional, non-destructive visualization of vertical root fractures using flat panel volume detector computer tomography; an ex vivo in vitro case report. Int Endod J 2005;38(12):904-13.

[38] Hagiya YK, Yoshioka T, Suda H. Logistic regression equation to screen for vertical root fractures using periapical radiographs. Dentomaxillofac Radiol 2008;37(1):28-33.

[39] Kajan ZD, Taromsari M. Value of cone beam CT in the detection of dental root fractures. Dentomaxillofac Radiol 2012;41(1):3-10.

[40] Tofangchiha M, Bakshi M, Shariati M, et al. Detection of vertical root fractures using digitally enhanced images: revese-contrast and colorization. Dent Traumatol 2012;28(6):478-82.

[41] Takatsu T, Sano H, Burrow MF. Treatment and prognosis of a vertically fractured maxillary molar with widely separated segments: a case report. Quintessence Int 1995;26(7):479-84.

[42] Kudou Y, Kubota M. Replantation with intentional rotation of complete vertically fractured root using adhesive resin cement. Dent Traumatol 2003;19(2):1157. 